Delft University of Technology

\title{
Reverse Engineering of existing reinforced concrete slab bridges
}

Harrewijn, T.L.; Vergoossen, R.P.H.; Lantsoght, E.O.L.

Publication date

2020

Document Version

Accepted author manuscript

Citation (APA)

Harrewijn, T. L., Vergoossen, R. P. H., \& Lantsoght, E. O. L. (2020). Reverse Engineering of existing reinforced concrete slab bridges. Paper presented at IABSE symposium 2020 ,

\section{Important note}

To cite this publication, please use the final published version (if applicable).

Please check the document version above.

\section{Copyright}

Other than for strictly personal use, it is not permitted to download, forward or distribute the text or part of it, without the consent of the author(s) and/or copyright holder(s), unless the work is under an open content license such as Creative Commons.

\section{Takedown policy}

Please contact us and provide details if you believe this document breaches copyrights.

We will remove access to the work immediately and investigate your claim. 


\section{Reverse Engineering of existing reinforced concrete slab bridges}

T.L. Harrewijn, R.P.H. Vergoossen

Delft University of Technology (The Netherlands) and Royal HaskoningDHV

E.O.L. Lantsoght

Delft University of Technology (The Netherlands) and Universidad San Francisco de Quito (Republic Ecuador)

Thomas.harrewijn@rhdhv.com

Abstract:

Most bridges in the Dutch infrastructure are built before 1985 and have experienced increasing traffic intensities and loads. On the other hand, the structural (design) codes have changed over the years. A frequently faced problem in practice is that the original design calculations and technical drawings of a large percentage of the existing bridge stock are unknown or lost. The refore, the current capacity of the bridge is unknown. The currently used method to map the reinforcement dimensions and amounts in an existing bridge is by (X-ray) scanning. As an al ternative, this work proposes Reverse Engineering of the existing bridges, by re doing (a correct) former bridge design with a known design year and load class as a starting point. Consequently, the Reverse Engineered bridge design can be assessed according to the current Eurocodes. A pa rametric study reveals different capacity margins in former structural bridge design than expected beforehand. Bending moment seems to be the governing failure mode where the main focus in literature laid on shearfailure.

Keywords: Reverse Engineering, existing bridges, former bridge design, capacity margin, assessment, parametric study, reinforced concrete.

\section{Introduction}

In the Netherlands, the first reinforced concre te (RC) slab bridges were constructed at the beginning of the twentieth century, and the ma jority of these bridges in the current bridge stock were built before 1985 . The first RC bridge $s$ we re not designed according to a prescribed code, because no prescribed regulation existed at that time. The first developed design code for RC structures in the Netherlands wasis the GBV [1] ('Gewapend

Beton Voorschrift' = 'Reinforced Concrete Code') in 1912. After every period of a p proximately ten ye ars, a new version of the code was published including increased knowledge in mechanics, ma terial properties and practical experiences. The ministry responsible for infrastructure publis hed in 1933 the VOSB design code [2] ('Voorschriften vo or het Ontwerpen van Stalen Bruggen' = 'Design codes for Steel Bridges') in addition to the GBV, which described load models.

$B$ ridges are categorised based on the ir type of l oading in the VOSB. Bridges designed for norma I tra ffic are categorised for a specific load class 
depending on the destination in the road network, see Table 1.

Table 1. Former traffic load classes, with the corresponding classification for VOSB1933 and VOSB1963, where a lower load class than 30 is omitted.

\begin{tabular}{ccc}
\hline $\begin{array}{c}\text { VOSB1933 } \\
\text { [Load class] }\end{array}$ & $\begin{array}{c}\text { VOSB1963 } \\
\text { [Load class] }\end{array}$ & Bridges: \\
\hline A & 60 & $\begin{array}{c}\text { in the national road } \\
\text { network; }\end{array}$ \\
\hline B & 45 & $\begin{array}{c}\text { in the main network } \\
\text { with accidental heavy } \\
\text { traffic; }\end{array}$ \\
\hline C & 30 & $\begin{array}{c}\text { not intended for } \\
\text { heavy traffic; } ;\end{array}$ \\
\hline D & - & $\begin{array}{c}\text { intended forlight } \\
\text { traffic (pedestrians)- }\end{array}$ \\
\hline
\end{tabular}

At the beginning of the 1960s, the VOSB1963 code [2] introduce d a different nota tion of load classes, see Table 1 . Since the 1960 s, ongoing increases in trafficintensities and loads have resulted in further changes to the governing load models. The cu rrently gove rning load model is given in NEN-EN 1991-2 [3], in which the difference between loading on the primary and secondary road network is reduced as compare d to previously used codes. As an alternative, in the Netherlands the (decentralized traffic load model ffor bridge s with span lengths up to $20 \mathrm{~m}$ and roads with maximum 125.000 trucks per year can be used.

On the other hand, the structural (design) codes have changed over the years. Existing structures a re designed using other materials and diffe re $n t$ ca pacity expressions. The main changes in ca pacity calculations are related to the transverse load distribution methods, the use of plain re inforcement bars versus ribbed bars, and the later introduction of code requirements for limiting the crack width. Upon assessment, the se structures may not fulfil the requirements a ccording to the current codes. Therefore, there is a need to investiga te if existing structure s me et the safety/reliability levels described in the current assessment codes $=\underline{w}, \underline{w}$ he re the lower I imit for structural safety is set to the 'usage level' with a reliability index of $\beta=3,3$.

A survey on bridges of municipalities [4] sh owe d that the records of existing bridges are incomplete. For an estimated $1 / 3^{\text {rd }}$ of the existing concrete bridges, the reinforcement la yout is known. Since these bridges are owned by municipalities, the majority of these bridge $s$ a re load class $B / 45$. As a result of the changes at the loading side (Table 1 ) and ca pacity side in the codes, summarised in Figure 1, and the la ck of information regarding these bridges, the re a re concerns regarding their structural sa fety. For example, a significant amount of records of $R C$ bridges are unknown and so the construction ye ar, the former load class and consequently the current structural capacity is unknown.

The currently used method to map the re inforcement bar diameters and spa cing in a $n$ existing bridge is by scanning the reinforce me $n t$ with an X-ray scanner. However, this method is not precise, causes a lot of traffic delays, and consequently costs a lot of time and money. Th is work proposes Reverse Engineering (RE) of the b ridge as an alternative. Figure 1 identifies fo u $r$ time periods between 1930 and 1970 for which the prescribed methods for capacity and loa ding in the codes are constant. As such, the construction year is an indica tor of the origin a lly used design method. In RE the bridge, the former design procedures are thus repeated, resulting in 
the originally assumed force distribution in the bridge deck, and the associated minimum required capacity. From this bending moment ca pacity, a reinforcement layout in te rms of ba $\mathrm{r}$ diameter and spacing can be assumed. Consequently, an assessment of this RE bridge with RE reinforcement can be performed with the current assessment codes. In case, crucial information is missing for the RE approach, X-ray scanning can be the backup solution. However, with historical documentation e.g. planning studies and area development plans, a substantiated estimation of the design ye $\mathrm{r}$ a nd the load class can be made.

\section{Preliminary study}

\subsection{Hand calculations}

To check the validity of the approach, a group of bridges with available documentation is RE first by hand-calculations. Former bridge design before the invention of the computer was all performed with hand-calculations. Therefore, the statical scheme is simplified as a beam, and skew is neglected. The group of bridges includes rectangular slab bridges with and without edge beams.

The distribution in the transverse direction was prescribed by the method from the applicable design code. Four methods are identified: three originate from the GBV design code, (one of which deviates significantly in terms of the resulting effective widths and will not be considered further), and the fourth method is developed by Guyon Massonnet [5].

Two methods to determine the bending moment capacity are identified: the $\mathrm{N}$ method, which uses a global safety factor by introducing allowable material stresses and assumes a linear concrete stress-strain relation, and the Crack-method, which uses the capacity of the structure at the moment of failure as a starting point, and describes a parabolic concrete stress-strain relation.
From the hand calculations, see Table 2, it can be concluded that the main reinforcement can be RE (almost) without overestimation of the capacity. The focus lays on the main reinforcement in the mid-span and at the midsupports of the bridges.

Table 2: RE reinforcement by hand calculations vs. records.

\begin{tabular}{|c|c|c|c|c|}
\hline \multicolumn{2}{|c|}{ Bridge } & $\begin{array}{c}\mathrm{RE} \\
{\left[\mathrm{cm}^{2}\right]}\end{array}$ & $\begin{array}{c}\text { Records } \\
{\left[\mathrm{cm}^{2}\right]}\end{array}$ & $\begin{array}{c}\text { Accuracy } \\
{[\%]}\end{array}$ \\
\hline \multirow{4}{*}{ A } & Span AB & 47 & 45 & 104 \\
\hline & Support B & 74 & 73 & 101 \\
\hline & Span BC & 54 & 57 & 95 \\
\hline & Support C & 74 & 73 & 101 \\
\hline \multirow{4}{*}{ B } & Span AB & 34 & 46 & 74 \\
\hline & Support B & 41 & 43 & 95 \\
\hline & Span BC & 27 & 27 & 100 \\
\hline & Support C & 34 & 39 & 87 \\
\hline \multirow{4}{*}{ C } & Span AB & 35 & 53 & 66 \\
\hline & Support B & 49 & 53 & 92 \\
\hline & Span BC & 49 & 53 & 92 \\
\hline & Support C & 49 & 53 & 92 \\
\hline
\end{tabular}

2.2 Findings of the preliminary study Former bridge design with formerly available tools and methods has led to simplified assumptions for the geometryand the need to calculate only the necessary. This can be see $n$ in practice by the following examples: 1) Simplifying the statica I scheme to a beam and omitting the effect of skew, 2) Calculating only governing mome $n t s$ in the mid-supports and mid-spans as a re sult of a common span ration of $\leq 0.8$ betwee $n$ the endspan lengths and mid-span lengths, 3) Calculating o ne dynamic amplification fa ctor (DAF) for a b ridge with different end- and mid-span le ngths, 4) Pe rforming a shear capacity che ck solely for beam structures, but not for slab bridges.

In this study, the shear capacity check is never encountered in former bridges design. However, RE of the shear capacity for bridges with and without edge beams shows sufficient shear capacity according to the former formulae for shear, see Table 3. Therefore, in former bridge design -bending moment is a ssumed to be the governing failure mode. 
Table 3: Shear capacity from the original design.

\begin{tabular}{cccc}
\hline Bridge & $\begin{array}{c}\text { Acting shear } \\
\text { stress } \\
{\left[\mathbf{k g} / \mathbf{c m}^{2}\right]}\end{array}$ & $\begin{array}{c}\text { Allowable } \\
\text { stress } \\
{\left[\mathbf{k g} / \mathbf{c m}^{2}\right]}\end{array}$ & $\begin{array}{c}\text { Unity } \\
\text { Check }\end{array}$ \\
\hline $\mathrm{A}$ & 7,8 & 7,9 & 0,94 \\
\hline $\mathrm{B}$ & 5,5 & 5,0 & 1,10 \\
\hline $\mathrm{C}$ & 6,6 & 7,0 & 0,94 \\
\hline $\mathrm{D}$ & 6,8 & 8,7 & 0,78 \\
\hline $\mathrm{E}$ & 7,8 & 8,7 & 0,90 \\
\hline $\mathrm{F}$ & 6,6 & 7,0 & 0,94 \\
\hline $\mathrm{G}$ & 6,9 & 7,3 & 0,95 \\
\hline $\mathrm{H}$ & 6,9 & 7,0 & 0,99 \\
\hline
\end{tabular}

The reinforcement in the edge beams is designed based on experience. The assumption is that the edge beams are designed for $100 \%$ of the permanent= and traffic loads from the midstrip, but this should be further examined. The amount of transverse flexural reinforcement is large ( $>=20 \%$ of the longitudinal reinforcement) and is not further examined in this study.

\section{Computer code}

\subsection{Automation of RE approach}

A RE tool is coded in Python [6] to automate the dimensioning of the required reinforcement according to the former design codes, as explained in the flowchart in Figure 2.

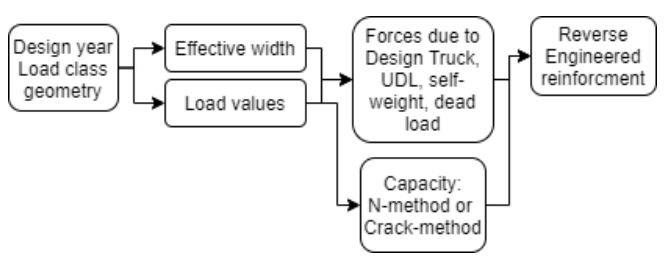

Figure 2: Flowchart of the RE-tool.

This tool uses the year of design, load class and the overall geometric dimensions of the bridge as input parameters. The user can select possible reinforcement diameters for which the tool will RE the reinforcement layout. The traffic load from the old design traffic model, the selfweight and the superimposed dead load from asphalt result in the governing sectional forces and moments for which the reinforcement is dimensioned. The bending moment capacity is increased by raising the reinforcement bar diameter until the Unity Check (ratio of bending moment caused by load combination to bending moment capacity) results below 1,0. Here, commonly used bar diameters are obtained from former design drawings (as encountered during the preliminary study) to provide the user with options. Consequently, the computer code can iterate through the options.

The validation of the model, see Table 4, shows for almost all RE bridges that the RE re inforcement is on average $10 \%$ lower tha $n$ the reinforcement amounts from the technical drawings. The RE approach is proven to be conservative and the capacity is never overestimated. Negligible deviations in the RE re inforcement are obtained betwee $n$ the hand calculations and the results from the computer code.

Table 4: RE reinforcement by computer code vs. records.

\begin{tabular}{lcccc}
\hline \multicolumn{2}{l}{ Bridge } & $\begin{array}{c}\text { RE } \\
{\left[\mathbf{c m}^{\mathbf{2}}\right]}\end{array}$ & $\begin{array}{c}\text { Records } \\
{\left[\mathbf{c m}^{\mathbf{2}}\right]}\end{array}$ & $\begin{array}{c}\text { Accuracy } \\
{[\%]}\end{array}$ \\
\hline \multirow{2}{*}{$\mathrm{A} A$} & Mid-span & 52 & 57 & 91 \\
\cline { 2 - 5 } & Mid-support & 71 & 73 & 97 \\
\hline \multirow{2}{*}{$\mathrm{B}$} & Mid-span & 28 & 27 & 104 \\
\cline { 2 - 5 } & Mid-support & 26 & 31 & 84 \\
\hline \multirow{2}{*}{$\mathrm{C}$} & Mid-span & 43 & 53 & 81 \\
\cline { 2 - 5 } & Mid-support & 50 & 53 & 94 \\
\hline \multirow{2}{*}{$\mathrm{D}$} & Mid-span & 46 & 49 & 94 \\
\cline { 2 - 5 } & Mid-support & 46 & 49 & 94 \\
\hline \multirow{2}{*}{$\mathrm{E}$} & Mid-span & 44 & 49 & 90 \\
\cline { 2 - 5 } & Mid-support & 44 & 49 & 90 \\
\hline \multirow{2}{*}{$\mathrm{F}$} & Mid-span & 33 & 37 & 89 \\
\cline { 2 - 5 } & Mid-support & 40 & 56 & 71 \\
\hline
\end{tabular}

Consequently, an assessment of the RE bridges ca $n$ be performed with sufficient robustness. Figure 3 shows the expansion of the flowchart from Figure 2 including the assessment me thodology. 


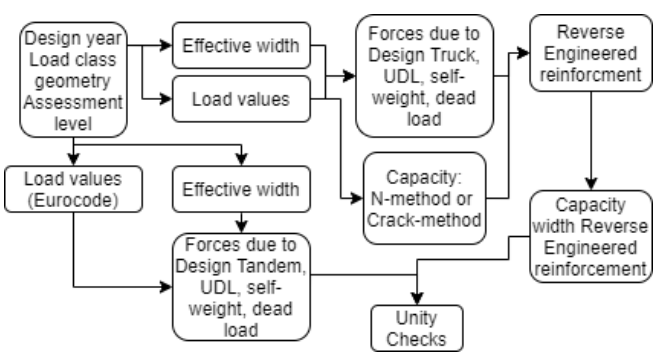

Figure 3: Flowchart of the RE-tool including the assessment.

The first application of the computer code is RE of a single existing bridge where a graphical user interface (GUI) guides the user to fill in the re quired parameters. The script then carries out the assessment of the RE bridge for the assessment level defined in the NEN8700 [7], specified by the user. An output screen $p$ resents the results of the RE forces and moments including the possibility to create an overvie w of a ll possible reinforcement configurations in terms of bar spacing and bar diameter. The former crack width control check is included if applicable to the former design code. The second part presents the re sults of the assessment: current design forces and moments, current capacity with RE re inforcement, and the resulting Unity Che cks.

\subsection{Parametric study}

The second application of the computer code is performing a parametric study to examine structural bridge design from diffe re $\mathrm{nt}$ de sign periods, geometrical configurations, and forme $r$ tra fficload classes. Figure 4 shows the RE pla in re inforcement per meter slab width for a midspan with a variable span length, with all other variables held constant, over the time span of 1930-1970. In case ribbed reinforcement with usually a higher steel quality is applied since the beginning of the sixties, the RE reinforcement will decrease for the last period 1962-1970.

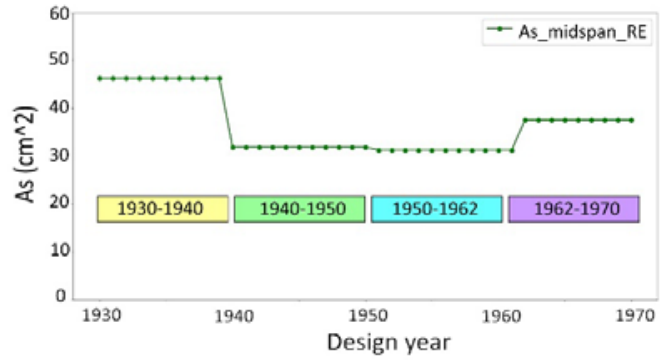

Figure 4: RE reinforcement amount at mid-span, over time.

\subsection{Assessment of RE bridges}

The capacity margin of the RE bridges is assessed according to the current Eurocodebased design codes. The traffic and permanent load including load factors from the assessment codes from the NEN8700 [7] /NEN8701 [8], RBK-1-1 [9] (Assessment code for existing structures) and the decentralized load model are applied. The level of assessment needs to be chosen, which includes the options to assess a bridge for reference periods of 1,15 and 30 years. The decentralized load model prescribes load and reduction factors that differ from the design traffic load model. From the results of each design period, it turned out that the periods 1940-1950 and 1950-1962 a re most critically designed. So, the focus of the study and the assessment lies on these periods. For the time period 1950-1962, the assessment according to currently governing codes showed Unity Checks for bending moment at the midsupports and mid-spans of larger than 1,0 see Figure 3.

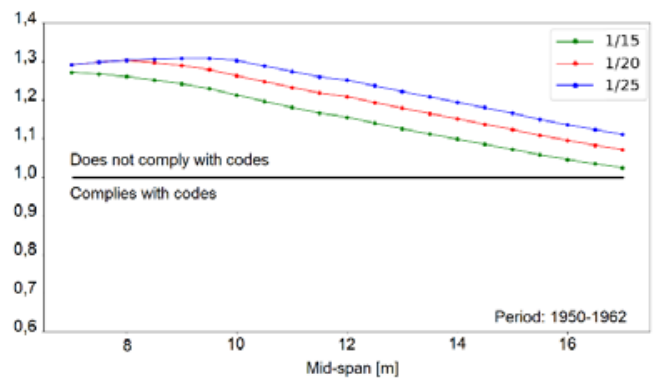

Figure 5: Unity Checks according to Eurocodes for bending moment of the midspans of a class $B$ 
bridge with RE reinforcement, for three different values of slenderness.

The Unity Checks for shear force result below 1,0 see Figure 6 . The script uses a minimum slab thickness, which explains the increasing capacity margin for small spans.

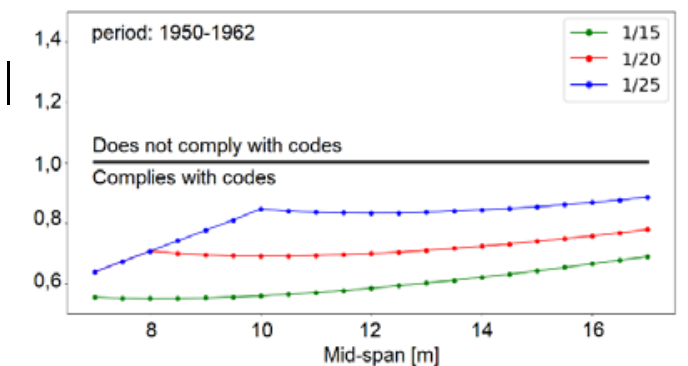

Figure 6: Unity checks for shear force of the midspans of a class $B$ bridge with $R E$ reinforcement for three different values of slenderness.

The assessment with the decentralised load model shows Unity Checks for bending moment at the mid-supports and mid-spans (Figure 7), as well as shear force below 1,0. In other words, when the decentralised load model is used, the code requirements are fulfilled.

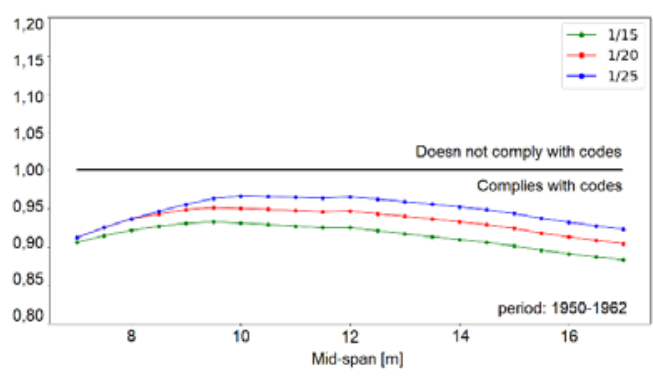

Figure 7: Unity Checks according to Eurocodes for bending moment of the midspans of a class $B$ bridge with $R E$ reinforcement with the decentralised load model, for three different values of slenderness.

Table 5 presents the overview of resulting Unity Checks for cross-sectional checks of bending moment at mid-span, at mid-support and for shear. The results concern former bridge designs according to load class B (with plain reinforcement) in the critical period 1950-1962. The RE bridges are assessed both for the Eurocode-based assessment codes, and including the decentralised load model. From the presented ranges, it follows that the most critical is the bending moment in the span, and that using the decentralised load model, the bridges Class B designed between 1950-1962 fulfil the code requirements.

Table 5: Resulting Unity Checks with Eurocodes of class $B$ RE bridges designed in the period 1950 1962, including the decentralised load model.

\begin{tabular}{ccc}
\hline $\begin{array}{c}\text { Class B } \\
\mathbf{1 9 5 0 - 1 9 6 2}\end{array}$ & Eurocode & $\begin{array}{c}\text { Decentralised } \\
\text { load model }\end{array}$ \\
\hline Mid-span & $1,0-1,30$ & $0,85-0,95$ \\
\hline Mid-support & $0,90-1,15$ & $0,75-0,90$ \\
\hline Shear force & $0,55-0,90$ & $0,45-0,80$ \\
\hline
\end{tabular}

Table 6 presents the overview of resulting Unity Checks for cross-sectional checks for bending at mid-span, at the mid-support and for shear. The results concern former bridge design according to load class A (with plain reinforcement) in the critical period 19501962. The RE bridges are assessed both for the Eurocode-based assessment codes, and including the decentralised load model. Again, span moment is most critical for assessment with the Eurocodes. In some cases now the Unity Check for shear is larger than 1,0. With the decentralised load model, the code requirements are met. Comparing Table 5 and 6 shows that the Class B bridges are more critical than Class A bridges.

Table 6: Resulting Unity Checks with the Eurocodes of class A RE bridges designed in the period 19501962, including the decentralised load model.

\begin{tabular}{ccc}
\hline Class A & Eurocode & $\begin{array}{c}\text { Decentralised } \\
\text { load model }\end{array}$ \\
\hline
\end{tabular}




\begin{tabular}{ccc}
\hline Mid-span & $0,95-1,09$ & $0,74-0,77$ \\
\hline Mid-support & $0,85-0,97$ & $0,60-0,80$ \\
\hline Shear force & $0,60-1,04$ & $0,40-0,85$ \\
\hline
\end{tabular}

During the preliminary study, for multiple bridges the amount of support reinforce ment and $\mathrm{span}$ re inforcement is equal. Bridges with support reinforcement based on the RE span re inforcement show Unity Che cks of 0,15-0,3 higher compared to the supports with RE re inforce ment. However, the applica tion of span re inforcement at supports is unknown due to the | lack of original design calculations.

\section{Discussion}

The parametric study provides a global insight into the current structural ca pacity of RC slab bridge s constructed in the period 1930-1970 with plain re inforcement bars. The study gives in sight in to the differe $\mathrm{nt}$ ca pacity margins according to current assessment methods of RC sla b bridges designed in the past. Former bridge design according to the former load classes $\mathrm{B} / 45$ and A/60 are often not indicative of shear force as a result of the amended regulations in the RBK-11 [9] after conducting experimental research. The focus within literature was mainly on the shear capacity of existing RC slab bridge $s$ ra the $r$ than on the bending ca pacity. The shear capa city was expected to be governing above the bending capacity of the existing RC slab bridges.

The assessment of RC slab bridges de signed for l oad class $A / 60$ with plain reinforceme $n t$ sh ow that the capacity margin for bending moment and shear force are more alike, due to a larger amount of required reinforcement for bending.

Assessment of individual cases provides full freedom in deciding the input parameters. With the use of the GUI, the user can decide every individual input parameter, as compa re $d$ to the parametric study, where the effe ct of a single parameter is evaluated. A different (more precise) bending moment-and/or she a r force capa city might be found with the individual assessment. In ge neral, the computer code is made to perform a quick assessment of a bridge with unknown reinforcement to get insight into the current structural ca pacity margin. If the Unity Che ck is larger than 1,0, the next Level of assessment ca $n$ be used, which is based on a linear elastic finite element model of the slab bridge [10].

A sensitivity study of the input parameters is performed with the computer code. The uncertainty in the input parameters from the engineering factor, execution factor, design year and load class affects the structural capacity. The computer code ran with the input parameters having a normal distribution, showed the largest effect for the uncertainty in the design year and load class especially around 1940 and 1962. Therefore, the design year and load class are crucial parameters in RE and assessment of an existing bridge. With these two parameters known, the accuracy of the RE reinforcement is within $10 \%$ of the amounts from the drawings. The assessment of these RE bridges

\section{Conclusion}

Si gnificant bending moment ca pacity margins a re o btained in structural designs of RC slab bridges in the period 1930-1970. The main contribution of th is research is that bridges designe d be twe e $n$ 1940 and 1962 show the most critical Unity Checks for flexure in the assessed period. It can be concluded that these bridges with RE re inforcement are found to be unsafe for bending mo ment according to the parametric assessme $\mathrm{nt}$ with the Eurocode. In the period 1940-1962 the following design assumptions are used: the dynamic amplification factor intro duce $d$ in the GBV1940 for concrete bridges, the traffic load class from the VOSB1933, the N-method to determine the cross-section ca pacity, and the effective width method from the GBV1940 and from the Guyon-Massonnet method.

The capacity margin for shear is found to be a Imost independent of the design period. The slenderness of the deck slab in RC sla b bridge design with low material qualities is the governing parameter for determining the she a $r$ ca pacity. 
In general, three groups of bridges from all existing RC slab bridges with plain reinforce me $\mathrm{nt}$ can be pointed out as most critical after a ssessment. First, the group of bridges with unknown design year and/or load class. Se cond, the group of bridges designed in 1940-1962 for l oad class $B$ with $\mathrm{N}_{\text {obs }}>125,000$ or span le $n$ gth $>$ $20 \mathrm{~m}$ or maximum vehicle load of $>60$ to $n$, for which the decentralised load model is not a pplicable. Third, the group (of unknown size) of b ridges with support reinforce ment based on the span reinforcement. This results in a prioritisation of the most critical existing RC slab bridges constructed.

B ridges designed in the period 1940-1962 with the support reinforcement based on the span re inforce ment and with mid-span length $s>10 \mathrm{~m}$ designed for load class $B / 45$, or with mid-span lengths $>11 \mathrm{~m}$ designed for load class $A / 60$, form the group with the most critical bending capa city in the assessment. However, the size of the group of former bridges designed a ccording to the se conditions is unknown.

Flexure is found to be the governing ductile failure mode over the non-ductile shear failure mode for RC slab bridges designed for load class B / 45 with plain reinforcement. The bending moment ca pacity is determined with RE reinforce ment and the shear capacity including the material qualities determined according to the NEN8700 [7], NEN8701 [8] and the RBK-1-1 [9].

Th is para metric study showed that the governing failure mode for RC slab bridges designed for load class B/45 with plain reinforceme $n t$ is be $n d i n g$ mo ment. These structures, and especially th ose designed between 1940-1962, have in gen e ra I a ductile failure mode where redistribution of forces occurs to avoid brittle fracture modes. Continuously, in the ductile failure mode of a $R C$ slab bridge, failure is initiated by yield ing of the re inforcement and cracking of the concrete in the te nsile stress area. Relating this conclusion to insufficient ca pacity during the assessment of a $n$ existing bridge, substantiation with visual inspection for cracks is evidential.

\section{References}

[1] Koninklijk Instituut va n Ingenieurs, Gewapend Beton Voorschriften (GBV1912), Afdeling Bouw e n Waterbouwkunde, 1912.

[2] Directie van Waterstaat, Voorschriften voor het ontwerpen van stalen bruggen (VOSB1933), Te chnical report, Ministerie van Waterstaat, 1933.

[3] NEN1991, Nationale bijlage bij NEN-EN19912+C1: Eu rocode1: Belastingen op constructiesDeel2: Verkeers belasting op bruggen. Normcommissie 351001 "Technische Grondslagen voor Bouw constructies", 2011.

[4] Mulder R., Onderzoek gemeentelijke b ruggen', Bouwend Nederland p.1-15. Bouwend Nederland, de vereniging va $n$ bouw-en infra bedrijven, 2015 .

[5] Hofman, J. and van der Vlugt, B., 'Berekening va $\mathrm{n}$ balkrooster- en plaatbruggen', Cement 8 , Nr.19-20, 1956.

[6] G. van Rossum, Python tutorial, Technical Report CS-R526, Centrum voor Wiskunde en In formatica (CWI), Amsterdam, 1995.

[7] NEN8700, Assessment of existing structures in case of reconstruction and disapproval-Bais Rules, Normcommissie 351001 "Technische Grondslagen voor Bouw constructies", 2011.

[8] NEN8701, Assessment of existing structures in case of reconstruction and disapprovalActions, Normcommissie 351001 "Technische Grondslagen voor Bouw constructies", 2011.

[9] RWS and GPO, Richtlijnen Beoordeling Kunstwerken (RBK), Beoordeling va $n$ de constructieve veiligheid va $n$ een bestaand ku nstwerk bij verbouw, gebruik en afkeur., 
Utrecht: RWS, GPO, 2013.

[10] Lantsoght, E. O. L., De Boer, A., \& Van der Veen , C. Levels of Approximation for the shear a ssessment of re inforced concrete slab bridges. Stru ctural Concrete, 18, 143-152, 2017.

Formatted:Indent: Left: $0 \mathrm{~cm}$ 